\title{
Study on Senile Driver Situational Awareness Model
}

\author{
Yanyang $\mathrm{Ma}^{1}$ and Yulei Liu²,a \\ ${ }^{1}$ Sichuan Agricultural University, Chengdu, China \\ ${ }^{2}$ Southwest Jiaotong University, Chengdu, China
}

\begin{abstract}
Along with the progress of the medical and living standards, the proportion of older people is rising, and at the same time in a wave of reform of Internet technology, on-board information technology changes with each passing day, in a variety of elderly drivers perceive situations, from the equipment situation, environmental situation, vehicle-mounted scenario system situation, combined with the on-board task main driving, information and communication, interaction and so on in interactive entertainment situation perception model.
\end{abstract}

\section{Background}

Due to the continuous progress of medical treatment and the improvement of living environment, the average life expectancy of the population has been extended, which leads to the aging trend of the global population. At present most parts of the world, especially developed countries have entered the aging society (more than $10 \%$ of the total elderly population aged 60 or 65 years of age or older population of more than $7 \%$ of the region or country). Table 1 shows a summary table of the proportion of people aged over 60 in major geographical regions of the world in different years (prepared by the United Nations population division), which shows that the aging trend in our country is very obvious. According to the statistics of the United Nations, by 2050, the absolute number of the elderly (aged 60 and above) in China will reach 440 million, accounting for $29.7 \%$ of the national population ${ }^{[1]}$. Aging has become an increasingly prominent social problem in China.

\section{Senior driver}

For people of any age, personal travel behavior is an important factor that affects their independence and ability to participate in society ${ }^{[2]}$. Therefore, it is of great significance for the physical and mental health of the elderly to meet their travel needs and make them enjoy the freedom and pleasure of driving as young people. With the increase of age, many psychological and physiological problems such as vision, perception, selfregulation and reaction ability of elderly drivers will directly affect their driving behaviors and the driving ability ${ }^{[3]}$. The results of studies in Australia and Sweden show that the elderly are more likely to make driving mistakes than the young people in both automatic and manual vehicles ${ }^{[4]}$. Relevant literature ${ }^{[5-8]}$ indicates that

\footnotetext{
a Corresponding author: tracey12@163.com
}

compared with young drivers, the accident rate of older drivers and the degree of injury in accidents are both higher. But with the deepening of informationization in the automotive industry, car environment with the introduction of more and more new information interface, function of elderly people in the face of increasingly complex intelligent information products encountered more obstacles, such as beckoned to don't understand the function of the information interface, information interface operation mode are not familiar with, the information products such as distance, and automotive information products in the early stages of development, considering the elderly drivers are not sufficient. Therefore, under the background of an aging society, the ease of use, improve vehicle information system make it not only meet the needs of ordinary drivers and satisfy the physical and mental needs of elderly drivers become an important subject.

China began to enter the aging time in the $1990 \mathrm{~s}$, from the national population development strategy research report forecast in the late $2040 \mathrm{~s}$, the population aged 60 and above, a 65 - year - old share will reach 30\%, $22 \%$ or more of the population ${ }^{[9]}$. Society is aging and the number of elderly drivers is rising. At present, the number of drivers aged over 60 and aged between 51 and 60 in China accounts for about $1 \%$ and $45 \%$ of the total number. It is predicted that in 2045 , the proportion of drivers over 65 will be about $14 \%{ }^{[10]}$. Since 2003 , the maximum age limit for applying for a driving license in China has been raised from 60 to 70 years old, and the consequent driving safety problems have become increasingly prominent. Elderly drivers in physiology, the respect such as the ability to learn, and increasingly complex traffic conditions and update the vehicle information system such as increased the operation of the driver and the cognitive load, has brought more challenges for elderly drivers. Definition of the elderly at home and abroad is different, the age of 60 or 65 an 
international watershed as the difference between the old and the rest of the population, the natural persons aged 65 and older is called the old people. According to the provisions of the law of the People's Republic of China on the protection of the rights and interests of the aged, natural persons over the age of 60 in China are called the aged.

\section{Situational awareness}

Context Awareness was proposed by Schilit ${ }^{[11]}$ in 1994. It originated from the study of universal computing and has become a hot research field in recent years. We are now generally USES Dey2000 years ${ }^{[12]}$ definition in his doctoral thesis, which can provide users with information from the user's situation is suitable for the people, time, location, activities, information or services. The purpose of situational awareness is to try to use human-computer interaction or sensors to provide the computing device with situational information about people and the environment of the device, and to make the computing device respond accordingly. KIM believes that the simplest definition of situational awareness is to acquire and apply the field environment, which includes adapting the field and using the field. Generally speaking, a situational awareness system consists of three parts: situational acquisition, situational presentation, and situational use. Situational awareness can be divided into active situational awareness and passive situational awareness according to different ways, mainly because of different ways of acquiring information. Can also be divided situation awareness into the reality of direct perception and internal contains two types of perception, mainly lies in the different types of information such as location, time environmental information and equipment information, etc, the latter as the characteristics of the user, habits, knowledge level and be fond of or divided into the original situation information and advanced situation information, the original situation data information such as location, time, brightness information, etc.

Table 1. The proportion of people over 60 years old in major regions of the world in different ages.

\begin{tabular}{|c|c|c|c|c|}
\hline Age/region & Africa & $\begin{array}{c}\text { In North } \\
\text { America }\end{array}$ & $\begin{array}{c}\text { In Latin } \\
\text { America }\end{array}$ & $\begin{array}{c}\text { The } \\
\text { European }\end{array}$ \\
\hline 1950 & 5.5 & 12 & 5.39 & 12.9 \\
\hline 1975 & 4.91 & 14.6 & 5.39 & 17.33 \\
\hline 2000 & 5.02 & 14.97 & 7.25 & 19.85 \\
\hline 2025 & 6.62 & 22.27 & 10.79 & 24.72 \\
\hline Age/region & Oceania & South Asia & East Asia & China \\
\hline 1950 & 11.29 & 7.56 & 7.53 & 7.63 \\
\hline 1975 & 11.13 & 4.97 & 8.23 & 7.96 \\
\hline 2000 & 19.85 & 6.43 & 11.45 & 10.71 \\
\hline 2025 & 24.72 & 10.59 & 19.59 & 19.34 \\
\hline
\end{tabular}

\section{In-vehicle control information system}

Vehicle control information system is an important part of the car is connected to the Internet, is the integration of digital information processing, wireless communication, navigation and positioning, embedded GIS, image display, and many other technology in the integration of high-tech products, is the intelligent transportation system (ITS) directly to the customer's part of the ${ }^{[13]}$. The on-board information system can provide the driver with entertainment, route guidance, real-time road conditions and taxi orders and payment information services. Vehicle information system in infinite input of information and the operation of the very limited interaction conflict: on the one hand, users of information systems is concentrate on the driving condition, on the other hand will vehicle information, location information, navigation information, user information and the Internet information into the on-board system, and because the richness, the variation of the LBS which caused by the type of information input is far greater than a PC or handheld device. The vehicle-mounted information system studied in this paper is limited to the vehiclemounted information system with multi-channel interaction characteristics in the context of Internet of vehicles. Vehicle information system: vehicle information, location information, navigation information, user information, communication and entertainment information system.

The United States, Europe and Japan are at the forefront of the technical research on vehicle-mounted information terminals. Their internet-connected vehicle systems have been widely used and the relevant industries are relatively mature. On - star company in the United States to MOTOROLA's wireless communication module, vehicle technology and comprehensive service center for an organic whole, the car to provide a full range of communications services, at the same time, ford also launched wing cast onboard Internet services. In Europe, the e-safety project involves the government, the vehicle factory, the automobile zero component factory, the service provider, the telecommunications provider, the platform manufacturer and so on, in order to further improve the driving Safety. In Japan, the g-book service, a smart-car terminal, has about $3 \mathrm{~m}$ users and is growing by 50,000 a year. Compared with developed countries in Europe and the United States, China's car networking industry started relatively late. Early mainly around the vehicular information platform of integration of all kinds of application services or development, since 2009, the independent brand of the big carmakers are began to focus on research and development new type of vehicle information terminal, Changan automobile, Geely launched new on-board system, etc. But for now, Oems, terminal factory, platform service providers in their scheme, couldn't connection forms, restricted the vehicle information terminal and car networking development of relevant industries. Therefore, the establishment of integrated intelligent vehicle information terminal design solutions and norms, has important practical significance. 


\section{Situational awareness model of elderly drivers and central control information system}

Firstly, by the physical characteristics of elderly drivers, driving in the process of situational factors and characteristics, the driving behavior of elderly drivers, comprehensive test research analysis, setting up the situation awareness in the elderly drivers driving model; This paper analyzes the experience requirements of elderly drivers driving cars from the aspects of the standards, application status and interactive design elements of information terminals. Analysis in the process of elderly drivers driving situation awareness must be matching with driving tasks one by one in order to obtain good situational awareness, and put forward can be used to further education, environment, compensation, auxiliary equipment check compensation to improve the interaction experience of vehicle information terminal equipment, through the design compensation to reduce the elderly drivers driving interaction requirements, thereby promoting driving task requires matching difficulty coefficient and situational awareness.

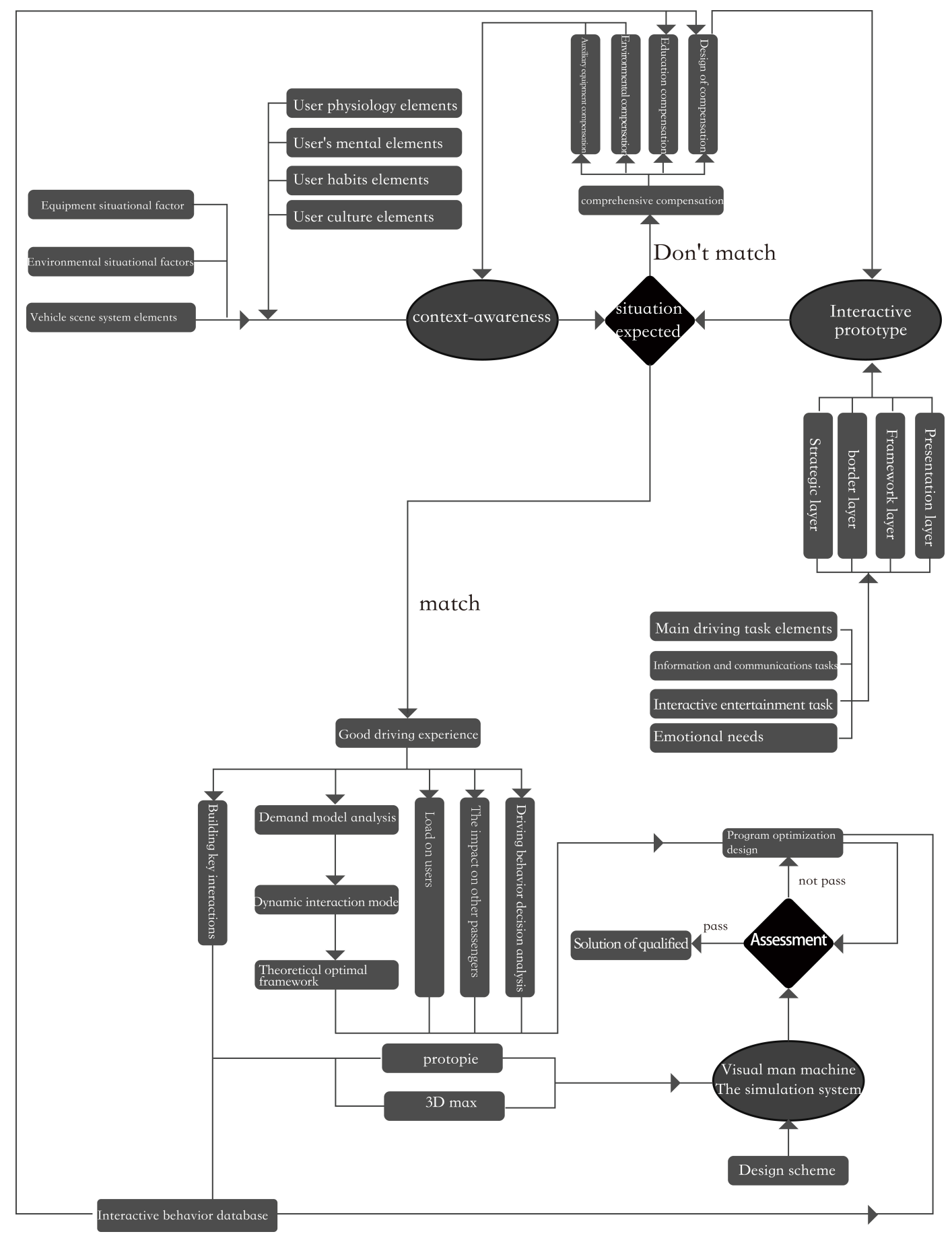

Figure.1 Research technology roadmap. 
On the basis of the above perception model, build elderly drivers driving key to driving and vehicle information terminal interactive elements, successively established elderly drivers driving demand for vehicle information terminal model, dynamic interaction model, the theory of optimal information framework, the experiment concluded that key interaction of physical, psychological load cases (electrical fatigue test, questionnaire, etc.) after the experiment, and the various interactions of grading. Through the field observation, video analysis (Observer behavior analysis software) analysis summary elderly drivers to other passengers riding in the process of driving, and graded according to affected or not, the results of this study can be used to plan or guidance for the optimization design of the new design.

To capture key interaction posture by motion capture device, generate interaction database, and then combine with production softwares 3 dmax software, through interactive database using interface simulation tool protopie visualization virtual interactive simulation platform, study the interaction of the database can be used in the visualization of design scheme evaluation and elderly drivers driving training activities, and key interaction database can be used to design or guidance for the optimization design of the new design. The detailed research technology roadmap is shown in figure 1 above.

\section{Conclusion}

The perception model, the situations of elderly drivers can port analysis perception elements from the physical sensation, from the design factors of port to analyze the design elements, and the matching relationship between them to further verify the perception model to explore the situation of compensation elements, so as to establish the dynamic model of the relationship between the three together.

\section{Acknowledgement}

Sichuan philosophy and social science key research base, Sichuan university humanities and social science key research base. Regional public management informatization research center (Grant NO. QGXH15-09).

\section{References}

1. United Nation. World Population Prospects [R]. New York, 1998.
2. Mc Gee, M A, et al. The description of activities of daily living in five centers in England and Wales Medical Research Council Cognitive Function and Aging Study [J]. Age and aging, 1998, (27): 605-613.

3. Anstey K j, Wood J, Lord S, et al. Cognitive, sensory and physical factors enabling driving safety in order adults [J]. Clinical Psychology Review, 2005, 25 (1): 45-65.

4. Selander. H, Bolin. I, Falkmer. T. Does Automatic Transmission Improve Driving Behavior in Older Drivers? [J]. Gerontology, 2012, 58 (2): 181-187.

5. DeMaria EJ. Evaluation and treatment of the elderly trauma victim $[\mathrm{J}]$. Clinics in Geriatric Medicine, 1993, 9 (2): 461-471.

6. RichterM, Pape HC, Otte D, et al. The current status of road user injuries among the elderly in Germany: a medical and technical accident analysis [J]. Journal of Trauma-Injury Infection\& Critical Care, 2005, 58 (3): 591-595.

7. Moran SG, McGwin G, Metzger JS, et al. Relationship between age and lower extremity fractures in frontal motor vehicle collisions $[\mathrm{J}]$. Journal of Trauma-Injury Infection\& Critical Care, 2003, 54 (2): 261-265.

8. Martinez R, Sharieff G, Hooper J. Three-point restraints as a risk factor for chest injury in the elderly $[\mathrm{J}]$. Journal of Trauma- Injury Infection \& Critical Care, 1994, 37 (6): 980-984.

9. National research group on population development strategy. National population development strategy research report [R]. 2007 [0] Curry RC, Greenberg JA, Kiefer RJ. NADS Versus CAMP Closed-Course 19 Comparision Eaminining "last-second" Braking and Steering Maneuvers under Various 20 Kinematic Conditions [R]. Washington DC: National Highway Traffic Safety Administration, 2005.

10. SHILIT B N, ADAMS N, WANT R. Context-aware computing applications. IEEE Workshop on Mobile Computing systems and Applications, 1994: 134-187.

11. DEY A K. Providing architectural support for building context-aware applications: [dissertation]. Atlanta: Georgia Institute of Technology. 2000.

12. KIM S W, PARK S H, Lee J B et al. Sensible appliance: applying context-awareness to appliance design. Personal and Ubiquitous Comuting, 2004, 8 (3-4): 184-191.

13. Yan Lei, Wang Kedong, Bai Geng, et al. Research and experiment on communication positioning mode in vehicle information terminals [EB/OL]. (2005-06) [2014-02-28]. htp://www.doc88.com/p-08239815274 65.html. 